\title{
Implementation of Differentiated Instruction: Conjoint Effect of Teachers' Sense of Efficacy, Perception and Knowledge
}

\author{
Visal Moosa \\ University Brunei Darussalam, Brunei Darussalam, Brunei, visal.moosa@gmail.com \\ Mariyam Shareefa \\ University Brunei Darussalam, Brunei Darussalam, Brunei, maree2098@gmail.com
}

\begin{abstract}
Existing literature suggests that teachers' sense of efficacy, their perception and knowledge of differentiated instruction (DI) are related to their implementation of differentiation. However, there is deficiency of research examining the predictive nature of those relationships. The purpose of this study is to examine the impact of teachers' perception and knowledge of differentiated instruction, and their sense of teacher efficacy on the implementation of DI strategies. The study employed a tool composed of validated items and constructs from previous studies to collect data from a sample of 101 elementary teachers in a single atoll ${ }^{*}$ of Maldives. Data were analyzed using SPSS 21.0. The results indicated that there was a significant correlation between teachers' knowledge of differentiated instruction and its implementation, and also between teachers' sense of efficacy and implementation of DI. Result of regression analysis showed that teachers' knowledge had a significant impact on their implementation of differentiated instruction. Recommendations were made for future research to investigate the effect of certain demographic variables and mediators on differentiation.
\end{abstract}

Keywords: differentiated instruction (DI), implementation, knowledge, perception, teacher efficacy

\section{INTRODUCTION}

Today's classrooms are composed of students with divergent characteristics with regards to their cultural, ethnic, linguistic, academic, socioeconomic and cognitive backgrounds, with a wide-ranging spectrum of learning needs (Ricketts, 2014). The increasing diversity of student characteristics alongside the notion of inclusive education demand teaching strategies that can cater for all students in mixed ability classrooms. The pressure on teachers to cater the diverse needs of the inclusive student population while at the same time trying to meet the requirements of the mandated curriculum has led to a myriad of efforts and ways of teaching and learning (Sheehan, 2011). One of such strategies is the strategy of differentiated instruction advocated by Tomlinson (1999).

Existing literature informs a number of factors (variables) which may influence teachers' implementation of DI strategies; they include, among others, knowledge (Baxter, 2013; Chien, 2015; McMillan, 2011; Nedellec, 2015), perception (Brentnall, 2016; Burkett, 2013; Davis, 2013; Usher, 2013), teacher's sense of efficacy (Casey, 2011; Dixon, Yssel, McConnell, and Hardin, 2014; De Neve, Devos, \& Tuytens, 2015; Holzberger, Philipp, \& Kunter, 2013; Johnson, 2010; Wertheim \&

\footnotetext{
* a group of islands clustered together for administrative purposes (equivalent to a district)

Citation: Moosa, V., \& Sahreefa, M. (2019). Implementation of Differentiated Instruction: Conjoint Effect of Teachers' Sense of Efficacy, Perception and Knowledge. Anatolian Journal of Education, 4(1), 23-38. https://doi.org/10.29333/aje.2019.413a
} 
Leyser, 2002), and challenges to implementation (Joseph, Thomas, Simonette, \& Ramsook, 2013; Martin, 2013; Roiha, 2014; Siam and Al-Natour, 2016).

However, the predictive nature of these factors on the desired behavior, which is the implementation of differentiated instruction strategies, is not adequately investigated. Furthermore, the influence of external variables like teaching experience and qualification, on the presumed relationships between the reported independent variables (knowledge, perception and efficacy) and implementation of DI has also not been examined sufficiently. It is argued that knowledge of the stated predictive relationships will facilitate implementation of differentiated instruction. The present study, thus, aims to contribute to the body of literature on differentiated instruction by investigating the nature and the strength of the predictive relationship between teachers' sense of efficacy, their perception and knowledge of DI, and implementation of the strategies. This paper, however, does not investigate the impact of teachers experience and qualification on those relationships.

\section{Research Questions}

In order to achieve the purpose of this study, it is guided by four research questions that are stated below.

1. What is the relationship between teachers' knowledge of differentiated instruction and their implementation of the strategy?

2. What is the relationship between teachers' perception of differentiated instruction and their implementation of the strategy?

3. What is the relationship between teachers' sense of teacher efficacy and their implementation of differentiated instruction?

4. What is the impact of the predictor variables (knowledge, perception and efficacy) on the outcome variable (teachers' implementation of differentiated instruction)?

Subsequently, the post-positive philosophy adopted in the study requires testable research hypotheses to be developed so that the answers to the research questions can be deductively attained. As such, for research hypotheses, one for each research question, were developed and tested using appropriate statistical analyses.

\section{REVIEW OF LITERATURE}

Increasing diversity in contemporary classrooms require schools to search for pedagogical approaches that focus on individualized instruction to improve learning for all students. In this regard, DI is, perhaps, the answer that educators are searching for (Logan, 2011). In fact, the rationale for implementing DI has been largely driven by the existence of increasingly diverse student population which can adversely affect student achievement (Bundoc, 2007). As such, proponents of DI base their arguments for adopting the approach -among others- on the positive effects it has on student achievement. Research advocating the use of differentiated instructional strategies for improving student achievement and closing the achievement gap is in abundance (see Connor, Morrison, \& Katch, 2004; DeBaryshe, Gorecki, \& Mishima-Young, 2009; O'Hare \& Lauria, 2011; Stager, 2007; Tulbure, 2011; Valiandes, 2015; Williams et al., 2013).

In the context of education, differentiation is defined as teachers' responsiveness to leaners' needs (Tomlinson \& Allan, 2000). DI is a teaching approach that allows teachers to embrace the essential differences that learners, as individuals, bring to the classroom (Tomlinson, 1999). The strategies of differentiated instruction have been recognized as one of the outstanding instructional innovations to cater the needs of student diversity (Usher, 2013). The concept is grounded in a number of well- 
established educational theories and contemporary research in education which acknowledge potential differences among individuals.

Gardner's (1983) Multiple Intelligence theory, for instance, is one of the major theories which explain differences in cognitive abilities of humans. According to Gardner $(1983,1999)$ humans are possessed with eight different types of intelligences: linguistic, logical-mathematical, spatial, bodily kinesthetic, musical, interpersonal, intrapersonal, and naturalist. These eight categories greatly contribute to the explanation of the disparities in human capacity, their preferred ways to learn and develop. As such, Gardner's theory signposts robust support to the concept of differentiated instruction as it provides theoretical grounds for different instructional treatment based on human intelligence (Robinson, 2017).

The concept of Zone of Proximal Development (ZPD) by Vygotsky (1978) is also in great support to DI. ZPD is the distance between the child's actual development level and the level of potential development under the guidance and support of a knowledgeable individual by means of scaffolding (Vygotsky, 1978). As claimed by the concept, learning will not occur outside this zone since it would then be either something which the individual has already learned or something which is unattainable at present due to limitations of existing knowledge in the individual. For this reason, considering the prior knowledge of the individual is essential for learning to take place which, thus, supports the concept of differentiated instruction.

The pioneer work of Carol Ann Tomlinson is considered the foundation for research on differentiated instruction by a number of researchers (McLean, 2010; Topley, 2010; Walker, 2005). Consequently, her model is adopted as the theoretical foundation for measuring implementation of DI in the present study. Tomlinson (2008) defines her model of DI as a proactive, student-centred instructional model that acknowledges individual differences on learning styles, motivation, abilities, and readiness to learn. Based on these factors, the model proposes four ways on how lessons can be differentiated. These are known as the key elements of the model of differentiated instruction; content, process, product, and environment (Tomlinson, 2000). Tomlinson explicates these four elements as;

“... (1) content--what the student needs to learn or how the student will get access to the information; (2) process--activities in which the student engages in order to make sense of or master the content; (3) products--culminating projects that ask the student to rehearse, apply, and extend what he or she has learned in a unit; and (4) learning environment - the way the classroom works and feels" (Tomlinson, 2000, p.2).

Review of existing literature informs that teachers' implementation of the strategies of DI is related to a number of factors including -on top of the complexity of the task let alone- teachers' knowledge, understanding and perception of DI, teachers' efficacy beliefs, and challenges to proper implementation of the strategies. Of these, teachers' knowledge, perception and sense of efficacy are the variables of interest to the present study.

\section{Teachers' Knowledge of Differentiated Instruction}

Despite the potential benefits of differentiated instruction on student achievement, and the plausibility of the approach in catering for individual differences in inclusive education settings of today's classrooms, implementation of the strategies by teachers are less frequent and inconsistent (Nedellec, 2015). Often, teachers misunderstand the purpose of differentiated instruction which results in teachers being hesitant towards adopting the strategies. While there could be several reasons for this inadequacy in the use of DI, a major influential factor is the complexity of the strategies itself (Tomlinson, 1999). Catering the diversity of needs of students by incorporating effective differentiated instructional strategies in the lesson while at the same time meeting the requirements of mandated curriculum leave teachers under increased pressure (Dixon et al., 2014). 
Despite teachers' awareness of the diversity of students and their belief that the traditional "one-sizefit-all" methods of instruction are less effective, implementation of differentiated instruction is not widely adopted. According to Nedellec (2015), even teachers who truly do differentiate their instruction may not do it on a regular basis. We argue that one major factor influencing teachers' implementation of the strategies of DI is that they lack accurate knowledge of the strategies. Teachers must be equipped with proper knowledge and understanding of how they can alter the content, process, product and the learning environment to match the learning profiles of the student. In other words, teachers must be provided with the pedagogical content knowledge necessary for effective implementation of differentiated instruction.

Our argument is supported by the existing empirical evidence from studies that investigated the relationship between teachers' knowledge of certain teaching strategies, including differentiated instruction, and their implementation of those strategies. Previous studies have specifically explored the relationship between teachers' knowledge, and their implementation of differentiated instruction (see, Baxter, 2013; Chien, 2015; McMillan, 2011; Nedellec, 2015) .

Chien's (2015) qualitative study, for instance, analyzed Taiwanese elementary school English teachers' perceptions and knowledge of differentiated instruction. The researcher concluded that teacher's reluctance to implement DI resulted from their lack of competence (in terms of knowledge) in the strategies. In a different study, analysis of interview data of 20 elementary teachers revealed that there is an association between teachers' training on differentiated instruction and its implementation in teaching (Nedellec, 2015). Similarly, Abbati's (2012) in-depth case study reported that strong competency and capability were among the several personal dimensions that significantly distinguish a low implementer of DI from a high implementer.

Among the studies which employed quantitative analyses, McMillan's (2011) research tried to examine the relationship between teachers' participation in differentiated instruction with their knowledge and frequency of using such strategies. The study revealed that there was a positive relationship between teachers' familiarity (knowledge and understanding of DI) and use of the strategies. Finally, the correlational analysis by Brentnall (2016) showed that there is a direct correlation between teachers' ability (pertaining to knowledge) to differentiate instruction and the amount of choice (pertaining to variation in teaching and learning) they provide to their students, indicating the existence of the relationship between knowledge and implementation of DI.

\section{Teachers' Perception}

Teachers' perception has been identified as a significant factor, among others, influencing teacher behavior. As such, studies examining teacher-thinking, over the past two decades, have been grounded on the underlying assumption that teacher thinking, beliefs, and attitudes are associated with their behavior and actions (Hall, 2005). In this regard, research on teachers' perception on various teaching strategies and associated relationships with the adoption of those strategies in teaching is abundant (see Brentnall, 2016; Burkett, 2013; Davis, 2013; Maddox, 2015; Smeeton, 2016; Usher, 2013; Watkins, 2013).

Researchers argue that teachers' perception on DI is essentially a question of their core belief that all students are capable of learning within a mixed ability setting (Brentnall, 2016). Brentnall (2016) added that the more the teachers perceive that they have the ability to differentiate instruction, the greater the choice teachers provide to students, indicating wider implementation of differentiation. Similarly, Burkett's (2013) qualitative study found that the use of DI strategies is prevalent when teachers perceive that differentiated instruction is essential in an effective classroom. In contrary, some studies emphasize that having positive perception of DI does not necessarily increase its implementation. Chen (2007), for instance, identified that although participants in the study stress the 
importance of differentiated instruction, they did not put the concept into their daily classroom practice. The reason for this, as delineated by the researcher, was lack of competence in differentiated instruction.

Nevertheless, many of the quantitative, correlational studies are in support of the reportedly positive relationship between teachers' perception and implementation of DI. For instance, Davis (2013) reported that there were moderate to strong positive relationship between teachers' dispositions and differentiation of instruction by content, process, product, and environment as perceived by the teachers. The study also found strong positive correlations between teachers' dispositions and differentiation of process and product as perceived by educational leaders. Similarly, Usher (2013) identified that teachers' perception was a significant predictor of implementation of differentiated instruction.

\section{Teacher Efficacy}

Review of literature on teacher efficacy reveals that the concept is often attributed to Rotter's (1966) concept of locus of control. Historically, considering Rotter's (1966) work as the conceptual basis, researchers at the Rand Corporation (RAND), first conceived teacher efficacy as the extent to which teachers believed that they could control the reinforcement of their actions (Goddard, Hoy, \& Hoy, 2000). However, the concept of teacher efficacy has been very much influenced by the wellrecognized theory of self-efficacy. Bandura (1977a, 1977b, 1986) defines teacher efficacy as a type of self-efficacy. According to Bandura, "efficacy expectation is the conviction that one can successfully execute the behavior required to produce the outcome" (Bandura, 1977b, p. 79).

The continued divergent conceptual explanations - between Rotter (1966) and Bandura (1977a) - of the concept of teacher efficacy eventually resulted in the proposal of an integrated model of teacher efficacy by Tschannen-Moran, Hoy, \& Hoy (1998). Tschannen-Moran et al. (1998) define teacher efficacy as teacher's beliefs in his or her capability to organize and execute courses of action required to successfully accomplish a specific teaching task in a particular context. We used the tool developed by Tschannen-Moran et al. (1998) to measure teacher efficacy.

The relationship between teachers' sense of efficacy and implementation of differentiated instructional strategies has been investigated extensively in previous studies. Much of these studies are in support of Bandura's (1977a, 1997) theory of self-efficacy in that teachers with higher levels of efficacy demonstrate considerable usage of the strategies of differentiated instruction. It is because teachers with high efficacy expectations believe that their persistent efforts will influence student achievement despite the intrusions of the challenging factors. As such, more efficacious teachers are in favor of inclusion, and are more likely to differentiate their instruction (Wertheim \& Leyser, 2002).

There is strong empirical evidence that teachers' self-efficacy and instructional quality are significantly correlated (Holzberger et al., 2013). Moreover, teachers with high sense of efficacy view that they are more prepared to differentiate instruction as compared to those with low sense of efficacy (Johnson, 2010). Additionally, Casey (2011) reported that there is a strong positive correlation between teachers' self-efficacy and perceived level of preparedness for differentiation, suggesting significant use of the strategies.

Existing literature not only suggests a positive relationship between teachers' self-efficacy and implementation of differentiated instruction, but also report teachers' self-efficacy having mediated and predictive relationship with DI implementation. For instance, De Neve et al. (2015) found that while teacher self-efficacy partially mediated the relationship between certain teacher behaviors and self-reported changes in DI practices, relationship between some other teacher behaviors and DI practices where fully mediated by teacher self-efficacy. De Neve et al. (2015) also found that DI 
practices are directly influenced by teacher self-efficacy which is in support of findings that teacher self-efficacy is a predictor of the way teachers report changes in DI practices (Suprayogi, Valcke, \& Godwin, 2017; M Tschannen-Moran \& Woolfolk, 2007). Findings of Dixon et al. (2014) are also in strong support of this where the authors reported that both teacher sense of efficacy and teacher efficacy are strong predictors of implementation of differentiated instruction in which the variables are reportedly accounted for $13.3 \%$ and $34 \%$ of variance in DI implementation respectively.

\section{Conceptual Framework}

Our conceptual framework is guided by both theory and empirical findings. Theoretically, it is grounded in the DI model of Tomlinson (1999). In this study, Tomlinson's model of DI is adopted to measure teacher's implementation of DI. In particular, teachers' embracing of DI strategies in their classroom is evaluated based on content, process, product, and environment as depicted in the DI model (Tomlinson, 1999). In addition to this, the reviewed literature, as reported above, acknowledge the existing relationships between teachers' efficacy, perception, knowledge and implementation of DI. These empirical findings have largely influenced our conceptual framework informing the hypothesized relationships among the variables as depicted in Figure 1. Figure 1, thus, shows the diagrammatic representation of our conceptual framework, which depicts that teachers' perception, knowledge and efficacy beliefs are related to their implementation of DI, where implementation is measured via differentiation by content, process, product, and the environment.

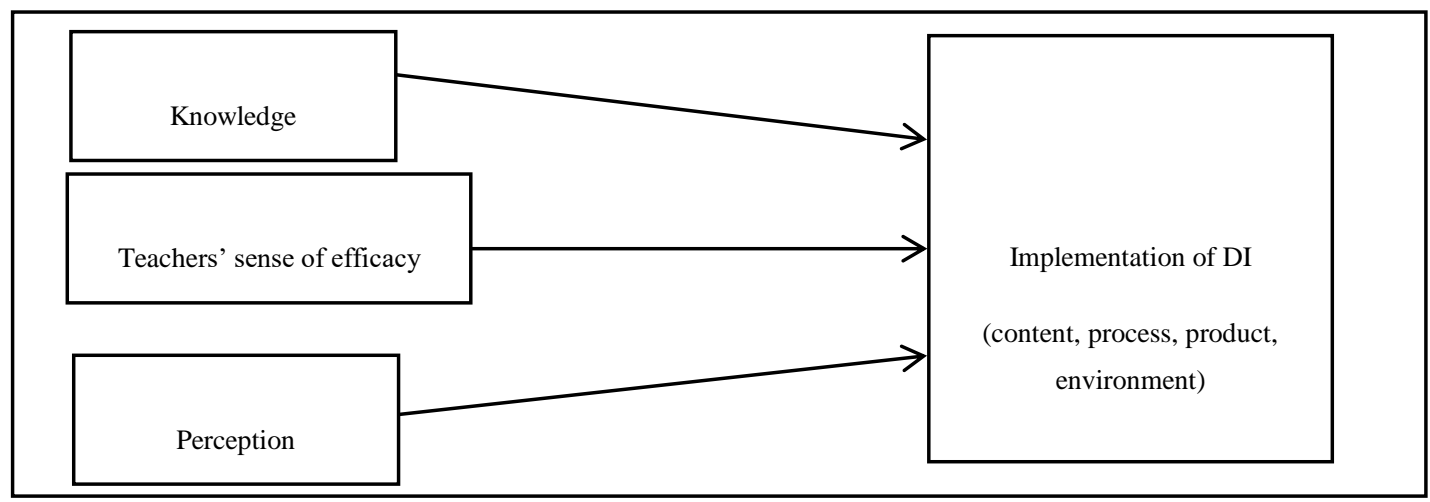

Figure 1

Conceptual Framework of the Study

\section{METHOD}

This study adopted a deductive approach guided by the post-positivist philosophy in social science research, in order to test the hypotheses that were derived from the conceptual framework given in Figure 1. The researchers chose a non-experimental, correlational design as a guiding framework for conducting the study, as the primary purpose of the study was to examine the (predictive) relationships between the variables involved. It is non-experimental since the researchers do not intend to manipulate or control the variable as in an experiment (Creswell, 2012); and it is correlational because the researchers intend to examine how two or more variables are related to one another(Creswell, 2012; Rockinson-Szapkiw, 2017).

The target population of the study was elementary public-school teachers from a single atoll of Maldives. A sample size of 99 was generated by the online sample size calculator, 'Raosoft', with the parameters set as follows; (i) A 5\% margin for error, (ii) a 95\% confidence level, and (iii) a $50 \%$ response distribution. The survey questionnaire was sent to all the schools in the atoll which consisted 
of about 130 teachers and all those that were returned were accepted. In this way, the researchers were able to collect a total of 101 completed surveys. These were considered random responses enabling inferences to be made on the target population based on the findings from the study (Banerjee \& Chaudhury, 2010).

The survey questionnaire that was employed consisted of items from previous studies, which the authors of those studies claimed to have passed through stringent validity and reliability procedures. In this regard, items for the knowledge and implemnetation scales were taken from Davis (2013) and McMillan (2011) while most of the items for the perception scale was taken from Usher (2013). Similarly, all the items for the teacher efficacy scale are taken from Tschannen-Moran and Hoy (2001). Items under all these scales were to be answered on a 5-point likert scale.

Data were analyzed using SPSS version 21.0. Prior to beginning data analysis, data were tested for assumptions of parametric statistics and scale reliability. The results of the normality test indicated that the data on the variables of knowledge and implementation were normally distributed while data on perception and efficacy were not. Besides, reliability analysis shows that all the scales of the survey obtained a score of at least .7 on Cronbach alpha, indicating good reliability of the scales and the tool in sum. Table 1 shows the specific alpha values for each of the four scales and sub-scales of knowledge and implication. The choice of statistical tests to be employed was made based on three factors; (i) the findings of the normality test, (ii) research questions, and (iii) statistical hypotheses. The specific tests that were employed are given when reporting the findings of each research question.

Table 1

Scale Reliability Scores

\begin{tabular}{lc}
\hline Scales and sub-scales & Cronbach alpha \\
\hline Perception & .78 \\
Knowledge & .96 \\
Content & .84 \\
Process & .92 \\
Product & .90 \\
Environment & .90 \\
Implementation & .94 \\
Content & .83 \\
Process & .91 \\
Product & .88 \\
Environment & .84 \\
Efficacy & .92 \\
\hline
\end{tabular}

\section{FINDINGS}

It was hypothesized that there is a positive correlation between the three independent variables (perception, knowledge and efficacy) and the dependent variable (implementation of DI). The three hypotheses thus formulated will, in turn, answer research questions one, two and three. In order to answer the first research question, correlation between knowledge and implementation was first studied at the level of sub-constructs (content, process, product, and environment). Since data on both of these variables were normal, Pearson correlation was performed to examine the hypothesized relationship between them. The results of the correlation analysis are displayed in Table 2. 
Table 2

Relationship Between Knowledge and Implementation

\begin{tabular}{lllllllll}
\hline Sub-constructs & 1 & 2 & 3 & 4 & 5 & 6 & 7 & 8 \\
\hline 1. Knowledge - content & --- & & & & & & & \\
2. Knowledge - process & $.61^{* *}$ & --- & & & & & \\
3. Knowledge - product & $.47^{* *}$ & $.71^{* *}$ & --- & & & & \\
4. Knowledge - environment & $.42^{* *}$ & $.66^{* *}$ & $.64^{* *}$ & --- & & & \\
5. Implementation - content & $.52^{* *}$ & $.33^{* *}$ & $.35^{* *}$ & 0.15 & -- & & \\
6. Implementation - process & $.39^{* *}$ & $.62^{* *}$ & $.51^{* *}$ & $.40^{* *}$ & $.45^{* *}$ & --- & & \\
7. Implementation - product & $.33^{* *}$ & $.43^{* *}$ & $.62^{* *}$ & $.31^{* *}$ & $.56^{* *}$ & $.75^{* *}$ & --- & \\
8. Implementation - environment & $.35^{* *}$ & $.43^{* *}$ & $.55^{* *}$ & $.59^{* *}$ & $.33^{* *}$ & $.59^{* *}$ & $.66^{* *}$ & --- \\
\hline$* * \mathrm{p}<.01$ & & & & & & & &
\end{tabular}

As evident from Table 2, there is a significant positive correlation between teachers' knowledge and implementation of differentiated instruction by content, $\mathrm{r}(78)=.52, \mathrm{p}<.01$. Similarly, there is also a significant positive correlation between teachers' knowledge and implementation of DI strategies by process, product, and environment; $\mathrm{r}(74)=.62, \mathrm{p}<.01, \mathrm{r}(82)=.62, \mathrm{p}<.01$, and $\mathrm{r}(82)=.59, \mathrm{p}<.01$ respectively. It is also observed that the strongest correlations occurred on the sub-constructs of process and product. Besides these correlations, total scores of the two scales were also investigated (using Spearman's rho) to gain an understanding of the overall correlation between knowledge and implementation of differentiated instruction (see Table 3). Spearman's rho was employed to investigate the relationship between total scores since data on some of the scales (perception and efficacy) violated the assumptions of normality. The results, thus obtained, indicate that there is a significant positive correlation between teachers' knowledge and implementation of DI strategies, $r$ $(68)=.61, p<.01$.

Spearman's rho was also employed to test the hypotheses for research questions two and three for the same reason stated before, the results of which are presented in Table 3. As seen from the table, there is no significant correlation between teacher's perception on differentiated instruction and their implementation of the strategies. The results, however, indicated that there is a significant positive correlation between teachers' sense of efficacy and their implementation DI strategies, $r(79)=.37, p$ $<.01$. These results allowed acceptance of the null hypothesis for research question two and rejection of the same for research question three. In addition to these findings, which are directly related to testing of the hypotheses, other significant and meaningful correlations are also observed from the table. In this regard, the results in Table 3indicate that there is a significant positive correlation between teachers' perception and their knowledge of DI, $r(67)=.33, p<.01$. Similarly, there is also a significant positive correlation between teachers' sense of efficacy and their knowledge of DI, $r(65)=$ $.28, p<.05$.

Table 3

Relationship Between Perception, Knowledge, Efficacy, and Implementation

\begin{tabular}{lllll}
\hline Constructs & 1 & 2 & 3 & 4 \\
\hline 1. Knowledge & --- & & & \\
2. Perception & $.33^{* *}$ & --- & & \\
3. Efficacy & $.28^{*}$ & 0.15 & --- & \\
4. Implementation & $.61^{* *}$ & 0.18 & $.37^{* *}$ & --- \\
\hline$* p<.05$ & & &
\end{tabular}

$* p<.05$

$* * p<.01$

The aforementioned results answered research questions one, two and three. Multiple regression was employed in order to determine the predictive relationship between the variables of perception, knowledge, and efficacy (independent variables) and implementation of DI (dependent variable). This 
would answer research question four. Prior to the analysis, the data were assessed on the required assumptions of multiple regression. The assessment of data revealed that it meets with the various statistical requirements and, so, do not violate the assumptions of multicollinearity, normality, outliers, homoscedasticity and independence of residuals (Pallant, 2007). While these assumptions generally apply to all the variables that are investigated, the normality assumption was checked only for the dependent variable (Field, 2005, 2009). Regression analysis proceeded once the data has got through the assessment of the assumptions. Table 4 displays the results of the multiple regression.

Table 4

Multiple Regression Analysis

\begin{tabular}{llllll}
\hline Variable & B & Beta & $t$ & Sig & Partial Correlation \\
\hline Constant & 28.405 & & 1.091 & .280 & -.043 \\
Perception & -0.187 & -0.034 & -0.333 & .741 & $.000 * * *$ \\
Knowledge & 0.587 & 0.606 & 5.813 & .062 & .237 \\
Efficacy & 0.309 & 0.188 & 1.903 & .067 & \\
\hline
\end{tabular}

$* * * \mathrm{p}<.001$

Model fit: $R^{2}=.434, F(3,61)=15.57, p<.000$

The regression model that was tested in this study states that implementation of DI strategies is a function of teachers' sense self-efficacy, their perception, and knowledge of DI. As see from Table 4, knowledge was the strongest predictor, having the strongest unique contribution to implementation of DI, when the variance explained by all other variables in the model is controlled for (Beta $=0.606, p<$ .000 ). Removing knowledge from the model would have reduced the $R^{2}$ (the amount of variance explained by the model) by $35.6 \%$ since the corresponding partial correlation coefficient is .597 . Other variables (perception and efficacy) do not have a significant unique contribution to the model. However, $R^{2}$ would have dropped by more than $5 \%$ if these variables were removed from the model and as such were decided to keep.

The overall fit of the model was $R^{2}=.434, F(3,61)=15.57, p<.000$, indicating that $43.4 \%$ of variance in implementation of DI was explained by the model (which includes the variables of efficacy, perception, and knowledge). Hence, our second hypothesis that teachers' sense of efficacy, perception and knowledge will have a significant impact on the implementation DI is accepted.

\section{DISCUSSION}

We hypothesized that there will be a positive correlation between teachers' knowledge of differentiated instruction and their implementation of those strategies. Results of the present study indicate that there are statistically significant, moderate to strong, positive correlations between knowledge and implementation of DI on each of the four domains of differentiation (content, process, product, and environment). Previous studies reported that teachers lack of competency was a major factor contributing to their reluctance in implementing DI strategies (Chien, 2015), and it is a significant personal dimension distinguishing low implementing and high implementing teachers of differentiated instruction (Abbati, 2012). The findings of the present study, thus, support our hypothesis and the majority of research findings on the relationship between knowledge and implementation of differentiated instruction.

Results of the regression analyses revealed that teacher's knowledge of differentiated instruction has an independent significant contribution to the variance in DI implementation. Knowledge alone explained $35 \%$ of variance in DI implementation in our regression model. This emphasizes the importance of providing relevant pedagogical content knowledge to teachers in the area of differentiated instruction. Findings reported by previous studies indicate that training provided to teachers on differentiated instruction significantly improve their implementation of DI strategies (Baxter, 2013; Nedellec, 2015). Furthermore, the importance of proper teacher training for successful 
implementing of differentiated instruction is also stressed by Brevik, Elisabeth, and Renzulli (2018). As such, findings of the present study, backed up by the already existing research findings, indicate that teachers' knowledge is the most significant factor having an impact on implementation of DI. Hence, it is claimed that knowledge of what differentiated instruction is and how it can be applied in the given context is necessary for successful implementation of the strategies.

Having stressed on the significant impact of knowledge on the implementation of differentiated instruction, we acknowledge that there exist some studies which report that teachers' implementation of DI may not be representative of their knowledge or understanding of the strategies (Whipple, 2012). It is because implementation of DI strategies may be hindered by a number of other factors including their unfamiliarity of available tools, and the immense amount of preparation time involved, coupled with lack of resources (Rodrigue, 2012). Hence, although our findings support the majority of the exiting findings signifying the impact of teachers' knowledge on implementation of DI, we urge that other contributing factors should be considered for proper facilitation of DI implementation.

In support of the preceding argument, we also hypothesized that there will be a positive correlation between teachers' perception regarding differentiated instruction and their implementation of such practices. Our hypothesis was guided and influenced by robust support from empirical studies that reported strong positive correlations between the dispositions teachers hold and their implementation of DI strategies (Davis, 2013), and that which reported significant predictive relationship between teachers' perception and implementation of DI (Usher, 2013). The results of this study, however, indicate that there is no statistically significant correlation between teacher's perception on differentiated instruction and their implementation of the strategies. Our finding, thus, rejects our hypothesis, and, is in partial disagreement with those studies reporting positive relationship between teachers' perception on DI and their implementation of those strategies. We call it a partial disagreement because the discrepancies in our findings with the referred literature could be resorted to the associated methodological differences in measuring perception that seem to exist among the studies.

Previous studies relating teachers' perception and DI implementation portray two distinctive views on perception; one on students' ability to learn regardless of the inherent diversities among them (Chen, 2007), and the other on teachers' ability to actually differentiate lessons (Brentnall, 2016). As we postulated, the findings reported by studies inclined to either of these views are apparently different. Chen (2007), for instance, found that there was a lack of teachers' use of differentiated instruction although they acknowledge it as a potential teaching strategy to cater for student needs (a student orientation of perception). On the other hand, Brentnall's (2016) study informed that grater implementation of DI was associated with teachers' positive perception that they have the ability to differentiate instruction (a teacher orientation of perception). We observe that there are differences in the views (regarding perception) adopted in these studies that are reflected in their findings.

While there may be ample room for theoretical explanations for the differences between these two viewpoints, unfortunately, it is not distinctively recognized by many of the exiting studies. As such, combination of items from these two dimensions were used in measuring teachers' perception regarding differentiated instruction (see Usher, 2013). In the absence of well-recognized measures of teacher perception on differentiated instruction I (Coubergs, Struyven, Vanthournout, \& Engels, 2017), it is not surprising to arrive at such findings as ours. In fact, we, too, used a mix of items from both of these views. As such, we urge that the discrepancies in the reported findings of the existing studies have to be investigated with due consciousness to how perception is measured. Our findings inform that researchers ought to be more cautious than now in studying teachers' perception on DI.

With regard to the third variable, teacher efficacy, the results of the present study are in support of our hypothesis that there is a significant positive relationship between teachers' efficacy and 
implementation of differentiated instruction. Our findings are in support of the vast majority of the existing studies which reported a positive correlation between teacher efficacy and DI implementation (De Neve et al., 2015; Dixon et al., 2014; M Tschannen-Moran \& Woolfolk, 2007). Moreover, there are strong theoretical arguments in favor of our findings. In this regard, the theory of self-efficacy provides robust theoretical foundation for the strong relationship. According to Bandura (1997), teachers with high self-efficacy about differentiated instruction will be better able to implement the DI framework since they believe that, by doing so, they can influence student achievement. Teachers' belief that they can actually differentiate together with the perceived benefits of using DI would naturally increase the use of those strategies. Hence, we propagate that creating necessary conditions to enhance teachers' efficacy believes is imperative for consistent implementation of DI strategies.

The forgoing theoretical explanation of the findings on teacher efficacy connects the discussion back to the debate on measuring teachers' perception on differentiated instruction. It is argued that teachers' perception on DI is essentially a question of their conviction that all students are capable of learning, regardless of their varied characteristics (Brentnall, 2016). If we agree to this definition of teachers' perception, then we ought to remove those items measuring teachers' ability to differentiate from the perception scale. This would, however, require a clear understanding of the distinctions between efficacy beliefs and perception. While efficacy beliefs are, in essence, perceptions held by individual, such beliefs are more inclined to their ability to perform a given task (Bandura, 1977a), whereas perception is a broader and more general construct. Hence, we claim that those statements which measure teachers' ability to differentiate instruction are more relevant to the construct of teacher efficacy for differentiation. On the other hand, those which measure benefits of differentiated instruction on students, particularly with their learning, are more applicable to measure teachers' perception on DI. Hence, the differences in the reported relationship between teachers' perception and their implementation of DI can, to a great extent, be minimized by sticking to a theoretically more appropriate measure of the construct. We argue that the statements should be more oriented towards the benefits of DI rather than teachers' ability to actually differentiate.

Coming back to the discussion on the relationship between teachers' efficacy and implementation of differentiated instruction, it is critical to highlight some other findings that are very closely linked to topic. In this regard, the results of the current study showed that, besides the significant correlation between efficacy and implementation, a significant positive correlation was also observed between knowledge and efficacy. This is to say that an increase in knowledge is associated with positive efficacy beliefs. Moreover, both knowledge and efficacy are positively related to implementation of differentiated instruction. Although it is not possible to claim a causative relationship between knowledge and efficacy, pertaining to the limitation in the design of this study, it is argued that knowledge is a critical factor for enhancing efficacy beliefs, which would, in turn, increase implementation of differentiated instruction. As such, we reiterate the emphasis on providing relevant and adequate knowledge of differentiated instruction.

Our final hypothesis, which tested the impact of the independent variables (knowledge, perception, and efficacy) on the dependent variable (implementation), states that teachers' implementation of differentiated instruction is a function of teachers' knowledge, perception, and efficacy. As indicated in the results, the proposed regression model has a significant impact on teachers' implementation of DI. Additionally, the model explained a magnificent variance in DI implementation with the variable of knowledge having a significant unique contribution to the model. Our findings are supported by the previous studies which reported a significant relationship between knowledge and implementation of differentiated instruction (Abbati, 2012; Baxter, 2013; Chien, 2015; McMillan, 2011; Nedellec, 2015).

Although our results indicate that there is a positive correlation between teachers' efficacy and implementation of differentiated instruction, our regression model did not show a significant 
independent contribution of it on DI implementation. The majority of the previous studies, however, reported a significant impact of teacher efficacy on DI implementation (De Neve et al., 2015; Dixon et al., 2014; M Tschannen-Moran \& Woolfolk, 2007). As such, we investigated our model further by removing all but teacher efficacy from it. Interestingly, the results showed that teacher efficacy, in fact, has a significant impact on DI implementation when tested individually. Hence, we assume that the impact of knowledge in our model is much stronger that it withholds the influence of teacher efficacy on DI implementation when tested together. Thus, we support the reportedly significant impact of teacher efficacy on implementation differentiated instruction although it is not significant when tested in our model.

\section{CONCLUSION AND RECOMMENDATIONS}

The purpose of this paper was to examine the impact of teachers' knowledge and perception DI, and their sense of efficacy, on the implementation of differentiated instruction. The results indicated that teachers' knowledge, perception and efficacy conjointly had a significant impact on teachers' implementation of differentiated instruction. Additionally, teachers' knowledge was identified having a significantly unique contribution to the impact on DI practices. Thus, we infer that teachers' knowledge, perception and their sense of efficacy are crucial factors in determining teacher behavior pertaining to differentiated instruction while recognizing that knowledge is the most significant among them.

Guided by the findings of this study, we put forward a few recommendations to policy, practice and research. Firstly, we advocate and support the provision of relevant and adequate training for teachers, both in-service and pre-service, in order to facilitate proper implementation of differentiated instruction in schools. Such training should be designed to improve teachers' ability to differentiate instruction based on a well-established framework such as the differentiated instruction model of Tomlinson (1999). Moreover, the training provided should ideally improve teachers' sense of efficacy for differentiating instruction while at the same time enhancing teachers' perception regarding the benefit of differentiated instruction on students.

Secondly, our regression model, which is made up of three independent variables (knowledge, perception and efficacy), was found to have a significant impact on the implementation of differentiated instruction. It also explained a great deal of variance in implementation of DI strategies. Hence, our findings offer reasons to consider all those factors when trying to implement differentiated instruction in schools. In fact, we noticed that removing the variables of perception and efficacy from the model significantly reduces the variance in DI implementation. Thus, we propagate that all the relevant factors, with particular emphasis on knowledge, must be taken into consideration for successful implementation of differentiating instruction.

Thirdly, future researchers must be cautious when choosing or developing a tool for measuring teachers' perception on differentiated instruction, particularly if the intention is to correlate teachers' perception with implementation of differentiated instruction. Evaluation of existing research against our findings reveals that those studies which used teacher-oriented items on perception report negative or no significant correlation whereas those which used student-oriented items report positive correlations with DI implementation. Future researchers might investigate to find out what might be the best approach to measuring teachers' perception on differentiated instruction under various conditions.

Finally, in the present study - despite the identified gap in existing research - we did not address any of the demographic factors which might have an impact on the implementation of DI. Future research can extend the regression model to include the effect of such variables as teaching experience and qualification on teachers' DI practices. Moreover, there is high possibility that teachers' efficacy can 
be a mediating variable among these relationships as reported by some of the existing studies. In fact, we found that teachers' knowledge and efficacy are related while at the same time their efficacy and implementation are also related. Keeping this in view, use of structural equation modeling to study the relationships simultaneously for moderating and mediating effects could be a promising methodological approach in future researches.

\section{REFERENCES}

Abbati, D. G. (2012). Differentiated instruction: Understanding the personal factors and organizational conditions that facilitate differentiated instruction in elementary mathematics classrooms. (Doctoral Dissertation). University of California.

Bandura, A. (1977a). Self-efficacy: Toward a unifying theory of behavioral change. Psychological Review, 84(2), 191-215.

Bandura, A. (1977b). Social learning theory. Englewood Cliffs, N.J. : Prentice Hall, c1977.

Bandura, A. (1986). Social foundations of thought and action: A social cognitive theory. Englewood Cliffs, NJ: Prentice-Hall.

Bandura, A. (1997). Self-efficacy: The exercise of control. New York: W. H. Freeman and Company.

Banerjee, A., \& Chaudhury, S. (2010). Statistics without tears: Populations and samples. Industrial Psychiatry Journal, 19(1), 60-65.

Baxter, J. D. (2013). How teacher training affects the implementation of differentiated instruction at the elementary level. (Doctoral Dissertation). Available at ProQuest Thesis and Dissertations. (UMI: $3551590)$.

Brentnall, K. (2016). Believing everyone can learn: differentiating instruction in mixed ability classrooms. (Doctoral Dissertation). College of Saint Elizabeth.

Brevik, L. M., Elisabeth, A., \& Renzulli, J. S. (2018). Student teachers' practice and experience with differentiated instruction for students with higher learning potential. Teaching and Teacher Education, 71, 34-45. https://doi.org/10.1016/j.tate.2017.12.003

Bundoc, K. S. (2007). Differentiated instruction in the elementary school reading classroom. (Doctoral dissertation). Available at Dissertation Abstracts (UMI: 3263282).

Burkett, J. A. (2013). Teacher perception on differentiated instruction and its influence on instructional practice. (Doctoral Dissertation). Oklahoma State University. Retrieved from https://shareok.org/bitstream/handle/11244/10960/Burkett_okstate_0664D_12634.pdf?sequence=1

Casey, M. (2011). Perceived efficacy and preparedness of beginning teachers to differentiate instruction. (Doctoral Dissertation). Available from ProQuest Dissertation and Thesis. (UMI 3450193).

Chen, Y. H. (2007). Exploring the assessment aspect of differentiated instruction: College EFL learners' perspectives on tiered performance tasks. (Doctoral Dissertation). University of New Orleans.

Chien, C.-W. (2015). Analysis of Taiwanese elementary school English teachers' perceptions of, designs of, and knowledge constructed about diffrentiated instruction in content. Cogent Education, 2, $1-16$.

Connor, C. M., Morrison, F. J., \& Katch, E. L. (2004). Beyond the reading wars: The effect of classroom instruction by child interactions on early reading. Scientific Studies of Reading, 8, 305-336. 
Coubergs, C., Struyven, K., Vanthournout, G., \& Engels, N. (2017). Measuring teachers' perceptions about differentiated instruction- The DI-Quest instrument and model. Studies in Educational Evaluation, 53, 41-54.

Creswell, J. W. (2012). Educational research: Planning, conducting and evaluating quantitative and qualitative research (4th ed). Boston: Pearson Education, Inc.

Davis, T. C. (2013). Differentiation of instruction in regular education elementary classes: An investigation of faculty and educational leaders' perceptions of differentiated instruction in meeting the needs of diverse learners. (Doctoral Dissertation). Available at ProQuest Thesis and Dissertations. (UMI: 3589970).

De Neve, D., Devos, G., \& Tuytens, M. (2015). The importance of job resources and self-efficacy for beginning teachers' professional learning in differentiated instruction. Teaching and Teacher Education, 47, 30-41.

DeBaryshe, B. D., Gorecki, D. M., \& Mishima-Young, L. N. (2009). Differentiated instruction to support high-risk preschool learners. NHSA Dialog, 12(3), 227-244.

Dixon, F. A., Yssel, N., McConnell, J. M., \& Hardin, T. (2014). Differentiated instruction, professional development, and teacher efficacy. Journal for the Education of the Gifted, 37(2), 111127.

Field, A. (2005). Discovering statistics using SPSS (Second Ed). London: SAGE Publications Ltd.

Field, A. (2009). Discovering statistics using SPSS (Third Ed). London: SAGE Publications Ltd.

Gardner, H. (1983). Frames of Mind: The Theory of Multiple Intelligences. New York: Basic Books.

Gardner, H. (1999). Intelligence Reframed. New York, NY: Basic Books.

Goddard, R. D., Hoy, W. K., \& Hoy, A. W. (2000). Collective teacher efficacy: Its meaning, measure, and impact on student achievement. American Educational Research Journal, 37(2), 479-507.

Hall, L. A. (2005). Teachers and content area reading: Attitudes, beliefs and change. Teaching and Teacher Education, 21(4), 403-414.

Holzberger, D., Philipp, A., \& Kunter, M. (2013). How teachers' self-efficacy is related to instructional quality: A longitudinal analysis. Journal of Educational Psychology, 105(3), 774-786.

Johnson, D. (2010). Learning to teach: The influence of a university-school partnership project on preservice elementary teachers' efficacy for literacy instruction. Reading Horizons, 50(1), 23-48.

Joseph, S., Thomas, M., Simonette, G., \& Ramsook, L. (2013). The impact of differentiated instruction in a teacher education setting: Successes and challenges. International Journal of Higher Education, 2(3), 28-40.

Logan, B. (2011). Examining differentiated instruction: Teachers respond. Research in Higher Education Journal, 13, 1-15.

Maddox, C. (2015). Elementary ( K-5) teachers' perceptions of differentiated instruction. (Doctoral Dissertation). Available from Walden University.

Martin, P. C. (2013). Role-playing in an inclusive classroom using realistic simulation to explore differentiated instruction. Issues in Teacher Education, 22(2), 93-106.

McLean, V. M. (2010). Teacher attitude toward differentiated instruction in third grade language arts. (Doctoral Dissertation). University of Southern Mississippi. 
McMillan, A. (2011). The relationship between professional learning and middle school teachers' knowledge and use of differentiated instruction. (Doctoral Dissertation). Walden University.

Nedellec, C. M. (2015). Teachers' understanding of differentiated instruction in Swiss elementary schools. (Doctoral Dissertation). Available from ProQuest Dissertations \& Theses. (Order No. 3718012).

O’Hare, L., \& Lauria, J. (2011). Differentiated instruction for adult learners in professional programs: Meeting the challenges of supporting diverse learners in nursing and teacher education. In 4th International Conference of Education, Research and Innovation (ICERI) (pp. 5042-5048).

Pallant, J. (2007). SPSS survival manual. Berkshire, England: Open University Press.

Ricketts, M. A. (2014). The lived experiences of teachers in implementing differentiated instruction in the inclusive classroom. (Doctoral Dissertation). Available from ProQuest Dissertations \& Theses. (Order No. 3645551).

Robinson, Q. E. (2017). Perceptions and adoption of differentiated instruction by elementary teachers. (Doctoral Dissertation). Available from ProQuest Dissertations \& Theses. (Order No. 10255701).

Rockinson-Szapkiw, A. J. (2017). Research categories and designs. Retrieved April 24, 2017, from http://drrockinsonszapkiw.com/elearning/quantitativeresearchguide/content/index.html

Rodrigue, A. (2012). An analysis of elementary school teachers' knowledge and use of diffrentiated instruction. (Doctoral dissertation). Available at Ed.D. Dissertations. (Paper 39).

Roiha, A. S. (2014). Teachers' views on differentiation in content and language integrated learning (CLIL): Perceptions, practices and challenges. Language and Education, 28(1), 1-18.

Rotter, J. B. (1966). Generalized expectancies for internal versus external control of reinforcement. Psychological Monographs: General and Applied, 80(1).

Sheehan, J. A. (2011). Responding to student needs: The impact on classroom practice of teacher perceptions of differentiated instruction. (Doctoral Dissertation). Available from ProQuest Dissertations \& Theses. (Order No. 3489941).

Siam, K., \& Al-Natour, M. (2016). Teacher's differentiated instruction practices and implementation challenges for learning disabilities in Jordan. International Education Studies, 9(12), 167.

Smeeton, G. (2016). Differentiated instruction: An analysis of approaches and applications. (Doctoral Dissertation). Available from ProQuest Dissertations \& Theses. (Order No. 10109251).

Stager, A. (2007). Differentiated instruction in mathematics. (Masters thesis). Aldwell College.

Suprayogi, M. N., Valcke, M., \& Godwin, R. (2017). Teachers and their implementation of differentiated instruction in the classroom. Teaching and Teacher Education, 67, 291-301.

Tomlinson, C. A. (1999). The differentiated classroom: Responding to the needs of all learners. Alexandria, Va: Association for Supervision and Curriculum Development.

Tomlinson, C. A. (2000). Differentiation of Instruction in the Elementary Grades. ERIC Digests, 1-7.

Tomlinson, C. A. (2008). Differentiated instruction. In J. Plucker \& C. Carolyn (Eds.), Critical issues and practices in gifted education: What the research says (2nd ed). USA: National Association for Gifted Children.

Tomlinson, C. A., \& Allan, S. D. (2000). Leadership for differentiating schools and classrooms. 
Alexandria, VA: ASCD.

Topley, B. M. (2010). Professional development implementation: Perceptions of elementary and middle-school teachers and administrators. (Doctoral Dissertation). Available from ProQuest Dissertations \& Theses. (Order No. 3455225).

Tschannen-Moran, M., \& Hoy, A. W. (2001). Teacher efficacy: Capturing an elusive construct. Teaching and Teacher Education, 17(7), 783-805. https://doi.org/10.1016/S0742-051X(01)00036-1

Tschannen-Moran, M., \& Woolfolk, H. A. (2007). The differential antecedents of self-efficacy beliefs of novice and experienced teachers. Teaching and Teacher Education, 23(6), 944-956.

Tschannen-Moran, M., Woolfolk Hoy, A., \& Hoy, W. K. (1998). Teacher efficacy: Its meaning and measure. Review of Educational Research, 68, 202-248.

Tulbure, C. (2011). Differentiated instruction for pre-service teachers: An experimental investigation. Procedia - Social and Behavioral Sciences, 30, 448-452.

Usher, L. R. (2013). Teachers perception and implementation of differentiated instruction in the private elementary and middle schools. (Doctoral Dissertation). Available at ProQuest Thesis and Dissertations. (UMI: 3565597).

Valiandes, S. (2015). Evaluating the impact of differentiated instruction on literacy and reading in mixed ability classrooms: Quality and equity dimensions of education effectiveness. Studies in Educational Evaluation, 45, 17-26.

Vygotsky, L. S. (1978). Mind and society. Cambridge, Mass: Harvard University Press.

Walker, K. (2005). Research brief differentiation.

Watkins, A. (2013). Teacher perceptions of the impact of differentiated instruction and formative assessments in improving academic achievement. (Doctoral Dissertation). Available from ProQuest Dissertations \& Theses. (Order No. 10125109).

Wertheim, C., \& Leyser, Y. (2002). Efficacy beliefs, background variables, and differentiated instruction of Israeli prospective teachers. The Journal of Educational Research, 96(1), 54-63.

Whipple, K. A. (2012). Differentiated instruction: A survey study of teacher understanding and implementation in a Southeast Massachusetts School District. (Doctoral Dissertation). Available from ProQuest Dissertations \& Theses. (Order No. 3525802).

Williams, R. T., Swanlund, A., Miller, S., Konstantopoulos, S., Eno, J., van der Ploeg, A., \& Meyers, C. (2013). Measuring instructional differentiation in a large-scale experiment. Educational and Psychological Measurement, 74(2), 263-279. 